\title{
Cyber Industry Networks as an environment of the Industry 4.0 implementation
}

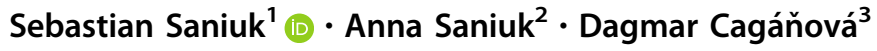

Published online: 3 July 2019

(C) The Author(s) 2019

\begin{abstract}
The fourth industrial (r)evolution called Industry 4.0 transfers production to a different dimension of productivity, flexibility and also mobility. Enterprises using advanced technologies such as Mobile Technologies, Big Data Analytics, Cloud Computing, Internet of Things, etc. and using intelligent resources (e.g. mobile devices, mechatronic machines, means of transport) communicating with each other via the Internet in real time can produce customized products quickly and at low cost. On the one hand the Industry 4.0 concept creates great benefits for the client, and on the other hand raises challenges for industrial enterprises. There is a need to improve existing and create new business models that will combine the potential of many enterprises and together create innovative, very modern production networks based on mobile technologies and the Internet of Things. The article presents the results of research about the creation of innovative production networks operating in the environment of advanced technologies within the Industry 4.0. The aim of the research is to develop the concept of creating temporary Cyber Industry Networks based on e-business platforms that integrate dispersed enterprise resources through mobile devices and mobile software, creating a temporary network in the situation of emerging business opportunities. The main benefit of such networks is the ability to manufacture products through geographically dispersed corporate resources. The Cyber Industry Network allows business processes through the integration of mobile technologies in real time to be managed, and enables to reduce costs, improve flexibility, and as a result increase the competitiveness of manufacturing enterprises.
\end{abstract}

Keywords Industry 4.0 · Industrial management · e-Business platform · Cyber Industry Network (CIN) · Mobility · Mobile technology

\section{Introduction}

The development of new, innovative technologies and the strong competition of Asian countries has led to the need to seek new solutions that increase the competitiveness of

Sebastian Saniuk

s.saniuk@wez.uz.zgora.pl

Anna Saniuk

a.saniuk@iizp.uz.zgora.pl

Dagmar Cagáňová

dagmar.caganova@stuba.sk

1 Faculty of Economics and Management, University of Zielona Gora, Licealna 9, 65-417 Zielona Gora, Poland

2 University of Zielona Gora, Licealna 9, 65-417 Zielona Gora, Poland

3 Slovak University of Technology in Bratislava, Jana Bottu c. 2781/25, 917-24 Trnava, Slovakia production companies on the market [1]. The concept of Industry 4.0 was created, often called the fourth industrial evolution or revolution. This concept transfers production to a different dimension of productivity, flexibility and also mobility. It is based on many different, very modern technologies at the same time, such as Mobile Technologies, Big Data Analytics, Cloud Computing, Internet of Things, etc. It also uses intelligent resources such as: mobile devices, mechatronic machines, means of transport. These resources communicate with each other directly or via the Internet in real time. The Industry 4.0 allows customized products quickly, at low cost through a step-by- 
step increase in productivity and efficiency to be manufactured.

The Industry 4.0 provides for the creation of large, very modern smart factories. It is also an opportunity for small and medium-sized highly specialized enterprises that together can create extensive production networks using digitization, mobile technologies, automation, advanced data analysis, etc. Such networks can offer many benefits to customers, enabling them to purchase products tailored to their tastes and needs and giving them the opportunity to create their own unique set of features of the product they buy. At the same time, there is a big challenge especially for small and medium-sized enterprises, which together in the form of production networks intend to manufacture products [2, 3]. There is a need to improve existing and create new business models that will combine the potential of many enterprises and together create innovative, very modern production networks [4].

The article presents the results of research about the creation of innovative production networks operating in the environment of advanced technologies within the Industry 4.0. The aim of the research is to develop the concept of creating temporary Cyber Industry Networks (CIN) based on e-business platforms that integrate dispersed enterprise resources through mobile devices and mobile software, creating a temporary network in the situation of emerging business opportunities. The main benefit of such networks is the ability to manufacture products through geographically dispersed corporate resources. The Cyber Industry Network allows business processes through the integration of mobile technologies to be managed in real time, and enables to reduce costs, improve flexibility, and as a result increase the competitiveness of manufacturing enterprises.

\section{Theoretical basis: Industry 4.0: customized production}

The Industry 4.0 concept imposes the production of customized products in which the customer chooses a product variant suited to his taste and needs. Customization is a challenge for enterprises, both large smart factories as well as small and medium-sized ones that together create a production network. It requires a completely different organization of production, whose priority is to shorten the time of the customer's order realization and low cost, which will be similar to mass production. In mass production, the customer orders the product already manufactured, and the fast delivery requirements apply only to distribution processes. Whereas customization causes that from the moment of receiving an order in a similar time and at a similar cost, processes related to production preparation, manufacturing processes and transport processes have to be implemented, which in practice is possible only with the use of many modern, innovative technologies and a rapid increase in efficiency and productivity [5].

As part of the Industry 4.0 concept, a fully integrated system of suppliers, manufacturers and also customers is created, called the Cyber-Physical System (CPS), composed of mechatronic, intelligent machines, mobile devices, robots, means of transport, etc. This system uses the Internet of Things, Big Data and Cloud Computing [6-8]. Implementation of advanced technologies causes that it is possible to create extended networks of geographically dispersed enterprises that jointly produce products and communicate via the Internet, using Cloud Computing technology. Such networks are called by the authors of the article Cyber Industry Networks. The advantage of such cooperation is the possibility of manufacturing in very modern supply chains and the use of spare capacity of individual network partners. Therefore, there is a need to conduct research on the development of forms of business cooperation networks that will jointly create a smart factory $[9,10]$.

\section{Results and discussion}

\subsection{Problems and challenges of forming the Cyber Industry Networks}

The idea of a production network called the Cyber Industry Network (CIN) means the manufacturing of joint production orders using fully automated processes of individual network partners, in which communication takes place via the Internet, and the necessary data is stored in the cloud (cloud technology) [11].The use of modern communication technologies ensures that all network partners have access to the necessary on-line information regardless of their geographical location. This enables the partnership development, which consists in combining the required resources, competences and know-how in order to better meet the constantly growing needs and expectations of the customer. Network partnership focused on the use of business opportunities also favors an effective competitive advantage in the market. The use of the potential of specialized network partners' resources and competences for joint production projects also increases the flexibility and speed of introducing new products to the market. It is particularly important in the case of customized product manufacturing.

There are many obvious benefits of the participation of enterprises in the network, but a selection process of network partners arises a lot of problems, especially in the SME's sector. During a network partner choosing, a number of functions should be included such as available 
production capacity, know-how, technology, represented quality level, financial condition, experience, ability to use the modern communication technologies, etc. Every presented area has a major impact on the results of joint implementation of production projects. Trust between partners, the need to invest in information technology and problems with its use become a particularly important aspects of cooperation. High investment costs in new technologies, including high implementation costs, are a significant barrier for small and medium-sized enterprises oriented to a network cooperation.

The research results of the International Federation of Robotics-IFR from 2017 have shown that the level of modern technologies use in manufacturing enterprises is very low. This is particularly visible in the assessment of the level of automation and robotics in Western European countries and central European countries. In the global production sector, there were used on average 85 industrial robots per 10,000 employees, while in Poland was only 36 robots. Compared with other countries in this part of Europe, Polish enterprises are characterized by the low results. For comparison, Czech industrial enterprises have 119 robots, Slovak 151 robots, and Slovenian companies have 144 robots per 10,000 employees. While German companies have 322 robots. Currently, the most automated country in the world is the South Korea, where the robotization density index in 2017 was 710 industrial robots per 10,000 employees [12].

Research conducted by Astor in 2015 shows that only about $15 \%$ of Polish industrial enterprises were fully automated, $76 \%$ of enterprises were characterized by partial automation, which means that the level of robotization and digitization of production is at a low level of advancement. Only $6 \%$ of enterprises in Poland introduce Industry 4.0. This means that Polish industrial enterprises are still at the stage of the third industrial revolution [13], which does not give hope for the rapid implementation of Industry 4.0. The financial barrier is one of the most frequently highlighted problems in the sector of small and medium-sized enterprises [11].

Another important barrier limiting the rapid application of the Industry 4.0 assumptions is the lack of a positive attitude to cooperation of enterprises, especially in the group of industrial SMEs. Initial research conducted on a selected group of 100 Polish enterprises operating in the industrial metal sector show a number of barriers related to both the experience of previous cooperation and the difficulties in creating various forms of network cooperation. Respondents also indicate problems with sell unused production capacity which often result from the inability to accurately estimate their availability and determine the sale price. $78 \%$ of surveyed enterprises need more than $24 \mathrm{~h}$ to check the availability of the device which can be used in the network. $61 \%$ of the surveyed enterprises can estimate the cost of using the resource. This means the need to automate the process of identifying the availability of resources through appropriate sensors of the production control information system.

Research conducted by ASTOR in 2016 shows that only about $36 \%$ of enterprises declare that their machine control systems are integrated with industrial software in a fully automated way, $59 \%$ of enterprises-manual input data into the system and $16 \%$ of enterprises-manual records on paper [14].

The research conducted by the Authors of the paper also identified a number of other problems related to the formation of cooperation networks. One of the most important is the search for a partner for cooperation which is often associated with the need to solve a number of problems related to both the risk of cooperation with an unknown company and the lack of methods of searching for a network partner. Based on the respondents' answers, the key problems of forming a network of enterprises are especially:

- lack of information systems (e-platforms) that support network creation (90\% of respondents);

- lack of transparent business models of network functioning (73\% of respondents);

- concerns about disloyal behavior of partners involved in the network (e.g. theft of know-how)-(45\% of respondents);

- problems with quickly finding a new network partner, especially in the case of a suddenly emerging business opportunity ( $41 \%$ of respondents);

- low quality of services (products) by potential partners (36\% of respondents).

In Industry 4.0, every enterprise in the network is perceived as an intelligent module that can be used to produce and deliver products to the customer through the entire logistics chain. The size of the enterprise is no longer important. Nowadays, considerations are:

- the level of technology used,

- the level of highly qualified staff,

- openness to unlimited communication using modern communication networks, block chain or IoT.

A model of enterprise cooperation based on a cyberphysical system (CPS) is a key condition for a development of the Cyber Industry Networks (CIN). CPS is open sociotechnical system composed of communicating mechatronic machines, devices, robots, means of transport, etc. CPS should ensure the collection and processing of data that affect physical processes throughout the production network. Due to the unlimited network connections of intelligent resources, it can be created system with a small 
human contribution in the production process, which only serves as supervisor and/or coordinator. Therefore, there is a need to conduct research on the development of business models describing the ways of creating CINs oriented towards a joint production venture, planning the load of geographically dispersed resources, production control and transparent way of financial settlement of partners.

Industry 4.0 requires the flexibility and dynamism for the formation of production networks of industrial enterprises. The accession of the enterprise to such a network requires, first of all, an initial assessment of the technological potential of the company, the possessed know-how, the employees' competencies and the ability to cooperate by the availability of resources [15].

\subsection{The concept of the e-business platform model for CIN forming}

The authors propose the concept of an e-platform available to companies with production capabilities that decide to create temporary Cyber Industry Networks oriented towards the common implementation of customized products. The platform is to support enterprises in creating and management of CIN in the event of emerging business opportunities that require the involvement of resources, know-how and specialized knowledge of employees, located in geographically dispersed enterprises. New technologies related to the Industry 4.0 allow for effective integration of the customer expecting a customized product with the production environment through the use of, among others, integrated e-commerce systems B2C, B2B or various types of dedicated e-platforms to support personalized orders. The customer using his own PC or mobile device (e.g. smartphone, tablet, etc.) will be able to make the specification of the ordered product, which will be designed, manufactured in a network of intelligent resources and delivered to the customer. The time of product delivery and the purchase price will be the decisive element of using this type of service. Therefore, there is a need to develop algorithms and tools that allow product realization in the network of available enterprise resources while minimizing production costs and logistics cost to be quick planned.

The concept of the e-business platform model is presented in Fig. 1.

The customer through electronic sales can determine the need for a personalized product by using the list of available options offered on the e-business platform of products. On this basis, the technological process of the product is developed, consisting of a set of operations that require the use of available resources of network partners. Based on the collected data, a set of network variants capable of timely project implementation including production and logistics costs is quickly made. Due to the geographic dispersion of enterprises, costs and logistic constraints are included in the network planning. The customer receives information about the date of product realization and price and selects one of the acceptable variants. The network prototyping algorithm is based on a sequence of checks of sufficient conditions, the fulfillment of which guarantees the completion of the product and its delivery to the customer within specified time. At the same time, a detailed resource utilization schedule is generated for each of the permitted CIN variants and information about the production plan is sent to network partners. An example of the schedule from the designed platform system can be seen in Fig. 2.

Each network variant is a set of selected enterprises for realization of individual tasks that can guarantee timely product realization while meeting the low price condition. Data about enterprise resources (cost of resource use, availability) are automatically transferred to the platform and secured against being made available to other network partners. This increases the security of the system against unfair competition. Each of the companies registered on the e-business platform has access only to information about appearing orders and may issue an available resource as an offer [16].

\section{Conclusion}

The concept of forming the Cyber Industry Networks presented in the paper using e-business platforms allows small and medium enterprises to combine their potentials and create smart networks capable of meeting competition in the era of the development of the idea of Industry 4.0. Creating common networks centered around the e-business platform allows for better use of the company's available resources, e.g. machines, mobile devices, mobile software, employees, equipment, tools, know-how, etc. It is an excellent motivating factor for investing in smart resources, mobile technologies and other innovation technologies related to the Industry 4.0 and selecting a development strategy focused on narrow specialization. Participation in networks helps to increase the use of resources and the productivity of partners. Practical formation of the CIN requires the construction of an e-business platform that offers customized products and the focus of potential network partners around it, whose intelligent resources will be used for emerging orders. It should be emphasized that creating such intelligent network structures consisting of many small and medium enterprises does not require large financial outlays. However, it necessary to change the way of company functioning and openness to unlimited communication between the e-business platform and partners. 
Fig. 1 The concept of creating temporary Cyber Industry Networks (CIN) based on e-business platform

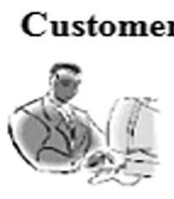

Project of personalized product
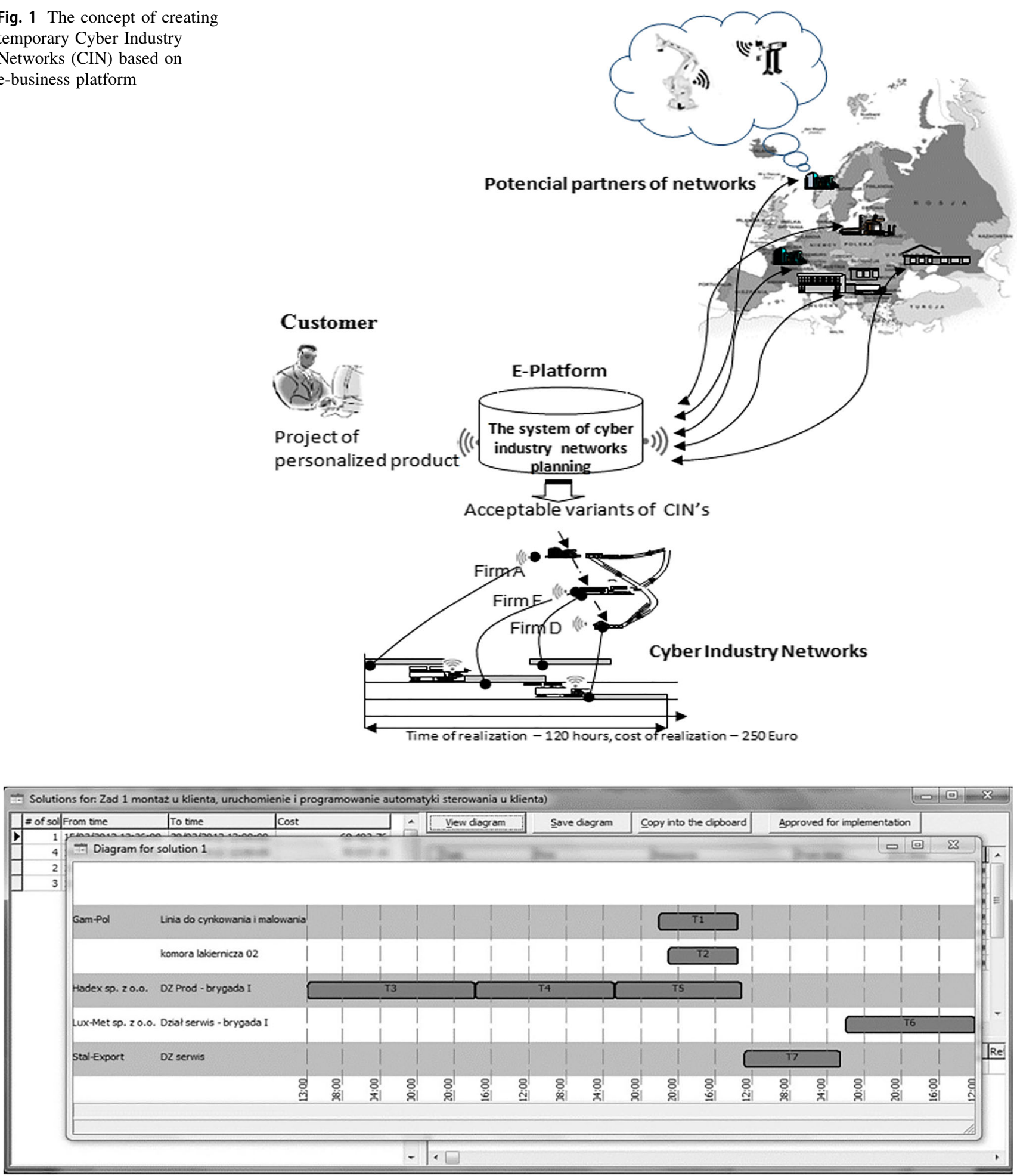

Fig. 2 Example of the resource loaded schedule for a specific variant of product realization in the Cyber Industry Network

The paper draws attention to the level of non-adaptation of Polish enterprises from the metal industry to the adaptation of the Industry 4.0 idea. The article identified, among others low level of automation and computerization of
Polish enterprises (lack of trust in other technologies; employment of qualified engineering staff.

Due to a low level of automation and computerization of Polish industrial enterprises (including the use of IT systems for operational management and production control), 
lack of trust in other enterprises often resulting from negative experiences of previous cooperation, lack of climate for investment in new technologies, low level of employment of qualified engineering staff, implementation of the Industry 4.0 assumptions and CIN creating is a huge challenge, especially in SME's sector.

The proposed e-business platform is designed to ensure intelligent communication of resources, in which enterprises in the network can safely exchange information in real time about available resources without a fear of data theft or know-how. One of the significant advantages of the network planning system proposed in the paper is the ability to create dynamic temporary networks of enterprises that can be simultaneously involved in many different projects (networks). Therefore, enterprises can easily establish cooperation and get a high level of use of available resources.

We believe that this model, especially given that it is based on the sharing of real time information, is of real value in the Industry 4.0 as it allows enterprises to exploit opportunities offered by the Internet of Things and Big Data in order to improve efficiency and profitability.

Open Access This article is distributed under the terms of the Creative Commons Attribution 4.0 International License (http://creative commons.org/licenses/by/4.0/), which permits unrestricted use, distribution, and reproduction in any medium, provided you give appropriate credit to the original author(s) and the source, provide a link to the Creative Commons license, and indicate if changes were made.

\section{References}

1. Walters, D., \& Buchanan, J. (2001). The new economy, new opportunities and new structures. Management Decision, 39(10), 822-823.

2. Corvello, V., \& Migliarese, P. (2007). Virtual forms for the organization of production: A comparative analysis. International Journal of Production Economics, 110, 5-15.

3. Franke, U. (2001) The Concept of Virtual Web Organizations and its implications on changing market conditions. Electronic Journal of Organizational Virtualness, 3. www.virtual-organiza tion.net. Accessed 1 October 2018.

4. Grabowska, S. (2016). Business model metallurgical company built on the competitive advantage. In: 25th anniversary international conference on metallurgy and materials (pp. 1800-1807), Brno, Czech Republic, 25th-27th May, 2016. Conference proceedings, Ostrava: Tanger Ltd.

5. Yi, W., Ma, H.-S., Yang, J.-H., \& Wang, K.-S. (2017). Industry 4.0: A way from mass customization to mass personalization production. Advances in Manufacturing, 5(4), 311-320.

6. Chui, M., Löffler, M., \& Roberts, R. (2010). The internet of things. The McKinsey Quarterly, 2(47), 1-9.

7. Olszewki, M. (2016). Mechatronizacja produktu I produkcji przemysł 4.0. Pomiary Automatyka Robotyka, 3, 13-28.

8. Cagáňová, D., Bawa, M., Rolando Delgado Sobrino, D., \& Saniuk, A. (2017). Internet of things and smart city. Zielona
Góra: Wydawnictwo Instytutu Informatyki i Zarządzania Produkcją, Uniwersytetu Zielonogórskiego.

9. Mrugalska, B., \& Wyrwicka, M. K. (2017). Towards lean production in industry 4.0. Procedia Engineering, 182, 466-473. https://doi.org/10.1016/j.proeng.2017.03.135.

10. Saniuk, S., \& Saniuk, A. (2018). Industry 4.0-technical-economic development perspective for the metallurgical production. In: 26th International Conference on Metallurgy and MaterialsMETAL 2017 (pp. 2288-2292), Brno, Czechy, 2017. Ostrava: Tanger Ltd.

11. Saniuk, S., \& Saniuk, A. (2018). Challenges of industry 4.0 for production enterprises functioning within Cyber Industry Networks. Management Systems in Production Engineering, 26(4), 212-216. https://doi.org/10.1515/mspe-2018-0034.

12. International Federation of Robotics. (2019). Robot density rises globally. Frankfurt. https://ifr.org/downloads/press2018/WR_Pre sentation_Industry_and_Service_Robots_rev_5_12_18.pdf. Accessed 1 February 2019.

13. Gracel, J. (2016). Industry 4.0 - kluczowe pytania i odpowiedzi. Automatyka, Podzespoty, Aplikacje, 6(10), 36-39.

14. Kowalkowska, J. Firmy produkcyjne inwestują w automatykę, ale dane nadal przetwarzają także ręcznie. https://www.astor.com.pl/ o-nas/artykuly/biznes/9964-firmy-produkcyjne-inwestuja-w-auto matyke-ale-dane-nadal-przetwarzaja-takze-recznie.html. Accessed 1 October 2018.

15. Soszyńska, E. (2012). Konwergencja technologiczna a potencjał społeczno-technologiczny krajów Unii Europejskiej. Metody Ilościowe w Badaniach Ekonomicznych, XIII(3), 191-201.

16. Saniuk, S., \& Saniuk, A. (2017). Decision support system for rapid production order planning in production network. In A. Burduk \& D. Mazurkiewicz (Eds.), Advances in intelligent systems and computing (Vol. 637, pp. 217-226). Berlin: Springer.

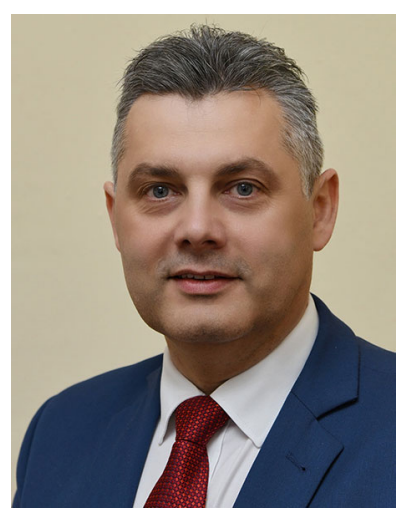

Sebastian Saniuk Assoc. Prof. Dr. in management and industrial engineering is employed as a professor at the Faculty of Economics and Management at the University of Zielona Góra. Since 2012 he has served as the Vice-Dean of Science. Since 2015 he is a member of the Committee of Production Engineering of the Polish Academy of Sciences. His research interests include issues related to management, industrial engineering and logistics, sustainable development, corporate social responsibility, particularly planning and control of production flow and modelling of production networks of small and medium enterprises, rapid prototyping, CSR in SME's. The results of his research have been presented in over 220 national and international scientific publications: journals, monographs and conference proceedings of national and international conferences (in countries including: China, Turkey, Slovakia, Czech Republic, Croatia, Portugal and Germany) including 39 papers in databases WOS and 29 in databases SCOPUS and has over 400 citations, 150 of them in quotation databases WOS and SCOPUS, h-index 7. During his career, he has conducted research under several grants awarded and funded by the Polish Ministry of Science and Higher Education, The National Centre for Research and Development and the European Union. 


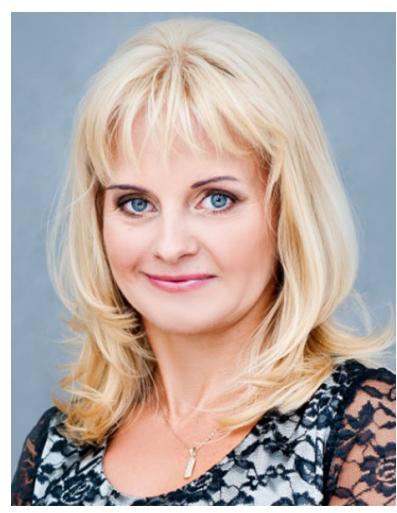

Anna Saniuk Assoc. Prof. in management and production engineering at the University of Zielona Góra, Poland, EU. Her research interests include controlling, managerial accounting, strategic and production management of industrial enterprises and sustainable development. She is particularly interested in measurement and assessment of business processes and company's effectiveness. She is a reviewer of several worldwide scientific journals and projects, a member of Scientific Committees of many domestic and international conferences. She has published more than 130 research manuscripts: 5 scientific monographs, 52 papers in the leading domestic and international journals, 43 conference proceedings and 30 book chapters including indexed in Scopus (28) and WoS (34) databases with quotations, WoS h-index 8. She took a part in national and international scientific and didactic projects. The most important of them were Standard Grant Projects of the International Visegrad Fund realized with universities from Czech Republic, Slovakia and Hungary.

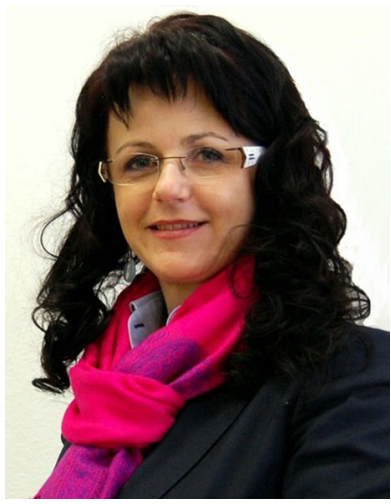

Dagmar Caganova Assoc. Prof. in Industrial Engineering, acts as vice dean for International Projects at the Faculty of Materials Science and Technology in Trnava, the Slovak University of Technology in Bratislava, Slovakia. She is also the co-founder of the European Alliance for Innovation in Slovakia, management committee member of E-COST (European Collaboration in Science and Technology) TN 1301 Sci Generation, the executive committee member in Danubius Academic Consortium (academic network for Integral Innovation), steering committee member of Danube strategy PA 7 Knowledge society- science, research, inovation and ICT for the Slovak Republic. Her professional interests, research topics and international collaborations are mainly focused on Intercultural and Innovation Management, Mobility and Smart Cities, Gender Diversity. She is the member of journal editorial boards, organiser, steering committee member of many domestic and international conferences, acts as tutor on Ph.D. study programme and has participated in numerous domestic and international projects as team member and as the project head. She is co-editor of Internet of Things, IoT Infrastructures 2014, part 2 and Smart City 360, 2015 published by Springer. To date she has published more than 200 publications, 7 scientific monographs, 33 papers in databases WOS and 35 in databases SCOPUS and has over 300 citations, 117 of them in quotation databases WOS and SCOPUS, h-index 5.

Publisher's Note Springer Nature remains neutral with regard to jurisdictional claims in published maps and institutional affiliations. 